\title{
Bullying escolar: a violência e preconceito nas formas do bullying entre estudantes do ensino fundamental em Campo Grande, MS $^{1}$
}

\section{School Bullying: the violence and prejudice in the bullying forms among elementary school students in Campo Grande, MS}

Bullying escolar: la violencia y los prejuicios en los caminos bullying entre estudiantes de la escuela primaria en Campo Grande, MS

Aparecido Francisco dos Reis ${ }^{2}$ Gabriel Zamian de Carvalho ${ }^{3}$

${ }^{1}$ Artigo construído a partir do projeto "A violência e o preconceito homofóbico no bullying escolar", coordenado pelo Prof. Dr. Aparecido Francisco dos Reis, com financiamento do CNPQ/UFMS.

${ }^{2}$ Mestre em Ciências Sociais, Doutor em Serviço Social pela UNESP. Professor Associado II da Universidade Federal de Mato Grosso do Sul (UFMS). Coordenador do Laboratório de Estudos da Violência, Gênero e Sexualidade (LEVS) da UFMS. E-mail: franreis@uol.com.br

${ }^{3}$ Graduado em Ciências Sociais da UFMS. Pesquisador do IBOPE Media de Porto Alegre, RS. E-mail: zamian_gabriel@hotmail.com 
Resumo: O objetivo deste artigo é discutir uma parte dos dados referentes às ocorrências de bullying homofóbico nas turmas de ensino fundamental da Escola Etalívio Pereira Martins em Campo Grande, MS. O material de campo que fundamenta essa análise foi coletado para o projeto de pesquisa sobre a violência e o preconceito homofóbico praticado nas formas do bullying escolar. O trabalho de campo consistiu em acompanhamento de aulas para se observar o comportamento dos alunos, anotações das conversas e brincadeiras e dos relatos de alunos. Os dados aqui discutidos apresentam as brincadeiras também conhecidas como zoações, como meio utilizado para reproduzir o preconceito sendo que em muitas destas são utilizados, inclusive, palavrões. Nessas brincadeiras, é construída uma heteronormatividade, que inferioriza comportamentos que fogem ao padrão normativo. A identificação de alunos homossexuais foi feita através de relatos. A ausência de uma autodeclaração do aluno pode ocorrer devido ao medo de esses homossexuais sofrerem violência, fazendo com que estes prefiram ficar no "armário".

Palavras-chave: bullying; homofobia; escola; heteronormatividade.

Abstract: The purpose of this article is to discuss some of the data relating to homophobic bullying occurrences in elementary school classes of Etalívio Pereira Martins School in Campo Grande, MS. The field material that underlies this analysis were collected for the research project on violence and homophobic prejudice practiced in the school bullying ways. The field researches consisted of accompanying classes to observe the behavior of students, notes of conversations and jokes and student reports. The data discussed here show the games also known as zoações as a means used to reproduce prejudice and in many of these are used, including profanity. In these games, it is built one heteronormativity, which diminishes behaviors that are beyond the normative standard. The identification of homosexual students was done through reports. The absence of a self-declaration of the student may be due to fear that these homosexuals have fear of violence, making them prefer to stay in the "closet".

Key words: bullying; homophobia; school; heteronormativity.

Resumen: El propósito de este artículo es discutir algunos de los datos de ocurrencias acoso homófobo en las clases de la escuela primaria de Etalívio Pereira Martins School en Campo Grande, MS. El material de campo que es la base de este análisis se recogió para el proyecto de investigación sobre la violencia y el prejuicio homofóbico se practica en las formas de acoso escolar. El trabajo de campo consistió en que acompaña a las clases para observar el comportamiento de los estudiantes, notas de las conversaciones y chistes y los informes de los estudiantes. Los datos discutidos aquí muestran los juegos también conocidos como zoações como un medio utilizado para reproducir los prejuicios y en muchos de ellos se utilizan, incluyendo malas palabras. En estos juegos, uno se construye Heteronormatividad que disminuye los comportamientos que están más allá del estándar normativo. La identificación de los estudiantes homosexuales se realiza a través de informes. La ausencia de una autodeclaración del estudiante puede ser debido al temor de estos homosexuales tienen miedo a la violencia, por lo que prefieren permanecer en el "armario".

Palabras clave: bullying; homofobia; la escuela; heteronormatividad. 


\section{INTRODUÇÃO}

O bullying no ambiente escolar é a ação motivada por atitudes discriminatórias de uma pessoa ou um grupo contra um indivíduo ou grupo social em situação de vulnerabilidade, sendo também a manifestação de diversos tipos de preconceitos contra aqueles que destoam dos padrões normativos da sociedade. O bullying homofóbico é uma dessas manifestações, em que indivíduos que possuem sexualidades consideradas como dissidentes ao padrão heteronormativo da sociedade são frequentemente alvo desta violência, podendo ela ser física e/ou psicológica.

Com base nos estereótipos homossexuais criados pela sociedade e com o significado sexual de alguns palavrões, alguns alunos podem sofrer o bullying homofóbico devido à representação de seus atos motores, gestos e fala estereotipada, sendo também, em várias ocasiões, a comparação do comportamento do homossexual ao comportamento feminino.

É comum encontrar, entre adultos, pessoas que carregam consigo marcas e traumas que adquiriram na escola. São sequelas que evidenciam o prejuízo em aspectos essenciais à realização da vida, como dificuldades de lidar com perdas, comprometimentos nas relações afetivas, familiares e sociais ou no desempenho profissional.

Essas pessoas foram submetidas às diversas formas de maus-tratos psicológicos, verbais, físicos, morais, sexuais e materiais, através de zoações, apelidos pejorativos, difamações, ameaças, perseguições e exclusões. Diversas vezes, esses preconceitos estão em brincadeiras, estas caracterizadas como próprias da idade, mas que evidenciam as relações desiguais de poder. 


\section{METODOLOGIA}

A metodologia desenvolvida ao longo do trabalho de campo teve a duração de um ano, abrangendo o segundo semestre de 2013 e o primeiro semestre de 2014. O acesso ao campo foi possível devido aos contatos entre os pesquisadores e professores da escola, travados no ano de 2012, em que os autores foram convidados a realizar oficinas com alunos e professores acerca da homofobia, do bullying, violência doméstica e contra a mulher, racismo e outros temas. Na ocasião, muitas questões referentes ao tema em epígrafe foram observadas, o que resultou, posteriormente num trabalho de campo mais sistemático sobre o ambiente escolar.

As turmas pesquisadas foram do 60 ao 90 ano do ensino fundamental do período matutino, nas aulas teóricas em sala, como Geografia, Linguagens e de Educação Física. Deve-se ressaltar que a escolha se deu em razão do convite dos professores dessas disciplinas. Focar nessas turmas facilitou aprofundar o acompanhamento e observações e obter dados com certa regularidade, e as aulas de Educação Física foram especialmente importantes neste trabalho, porque são aquelas nas quais ocorrem mais frequentemente a separação entre meninos e meninas para a realização das atividades recreativas e esportivas como poderá ser visto mais adiante.

As falas dos alunos foram obtidas através de conversas informais, não sendo construído um roteiro para guiar, nem as conversas foram gravadas. Assim, durante o texto, serão comentados os resultados dessas conversas informais com os alunos.

O período descrito permitiu um contato mais profundo com os sujeitos do campo estudado. Para tanto, o caminho escolhido para a coleta de dados, de certo modo, teve como referência o método etnográfico proposto por Malinowski (1984) no livro "Os Argonautas do Pacífico Ocidental". 
Malinowski apresenta uma preocupação em detalhar os princípios fundamentais que compõem o método de pesquisa da antropologia moderna, indicando os passos para sua execução. Entre os passos do método etnográfico, usou-se aqui a descrição dos elementos imponderáveis da vida escolar como os fenômenos cotidianos que foram observados por meio do acompanhamento contínuo das brincadeiras, comentários, conflitos, nos espaços comuns e durante as aulas. Outro ponto observado foram as palavras e expressões características da mentalidade de professores e alunos, que contribuem para a compreensão da sua visão de mundo, descobrindo os modos de pensar e sentir típicos dos sujeitos em questão.

É importante ressaltar que Malinowski rompeu com uma "antropologia de gabinete", na qual o investigador fazia suas análises a partir das informações obtidas junto a viajantes, mercadores e missionários, e inaugura um novo estilo de pesquisa pautado em um constante diálogo entre a observação participante e as descrições etnográficas. O método proposto por Malinowski compreende uma investigação aprofundada da vida nativa de modo que o etnógrafo possa compreender a organização social da vida tribal, sintetizada através da compreensão do ponto de vista nativo. A importância da obra de Malinowski fica explicitada, portanto, em seu trabalho monográfico, no qual estão expressas as possibilidades interpretativas suscitadas pelo método etnográfico.

Vários alunos, por vezes mais de um ao mesmo tempo, ficavam ao redor dos pesquisadores tanto na sala de aula, quanto no corredor da escola, e faziam perguntas, como nome, o porquê de estar ali, gosto musical, idade e qual curso fazia na universidade. Assim, foi necessário buscar categorias inteligíveis aos alunos, como por exemplo, falar sobre dos gostos musicais de cada um; explicar o que é uma universidade, o que se estuda e, por fim, informar claramente que a pesquisa era sobre preconceito, violência e homofobia e que as observações em sala eram necessárias para se fazer isso. 
Outra forma utilizada de manter contato com alunos foi a utilização do Facebook ${ }^{1}$, em que se pode conversar e se aproximar melhor do grupo pesquisado, facilitando as conversas no ambiente escolar.

Além disso, se garantiu que toda fala, entrevista ou anotações de campo, seriam anônima e que os participantes seriam identificados por pseudônimo. Esse processo interativo entre os sujeitos envolvidos na pesquisa possibilita ao longo do tempo, uma relação baseada na confiança. A questão da confiança é muito importante para a pesquisa; diversos antropólogos citam a importância de conseguir ser confiável para o grupo que pesquisa, como mostra, por exemplo, Foote-Whyte (1975):

Como Doc havia suposto, ninguém perguntou a meu respeito, porém mais tarde me contou que, quando fui ao banheiro, irrompeu uma conversa excitada em italiano e ele teve que convencê-los de que eu não era um policial federal [...] Fomos juntos diversas vezes ao estabelecimento de Chichi - até chegar o momento em que me atrevi a ir lá sozinho. Quando fui recebido de maneira natural e amigável senti que estava começando a ocupar um lugar em Corneville.

Possuindo a confiança dos alunos de que nada anotado seria passado para a coordenação ou direção da escola, eles puderam se sentir mais à vontade para conversar e se expressar com os pesquisadores.

Outro dado interessante do contanto, foram os comentários acerca da orientação sexual dos pesquisadores, sobretudo porque um deles usa cabelos longos, roupas pretas e costuma usar as unhas pintadas com esmalte, causando dúvidas, se seria ou não, homossexual. Esclarecido isso, passou-se a coleta de dados que será apresentada e discutida a seguir.

${ }^{1}$ https://www.facebook.com/ 


\section{REVISÃO BIBLIOGRÁFICA E DISCUSSÃO}

Na pesquisa de campo realizada, observou-se que o principal meio da reprodução do preconceito e do bullying homofóbico entre os alunos é através das brincadeiras e das piadas.

As brincadeiras aparecem constantemente em sala durante as aulas e podem ser consideradas como uma forma de interação social, nas quais se podem pontuar as diferenças de aprendizado entre os alunos, assim como estes demonstram de certo modo, a sua visão de mundo acerca da sexualidade dos colegas. Revelam diferenças de aprendizado, quando o professor pergunta algo para a classe e algum aluno emite uma resposta considerada como errada no contexto do conteúdo que está sendo ministrado. Nesse momento, vários outros alunos passam a zombar o que deu a resposta errada, por meio de termos depreciativos como "burro", jumento e outros. Isso tem como resultado a inibição daquele aluno, que provavelmente ficará calado das próximas vezes.

Outras brincadeiras bastante comuns se reportam às dimensões da sexualidade e da feminilidade. Muitas conversas entre os alunos do gênero masculino envolvem toques corporais, às vezes nas costas, ou comentários que procuram inferiorizar um dos participantes, com expressões que procuram associar negativamente o aluno à condição de homossexual ou à condição de mulher. Nesse sentido, ele será nominado pelos colegas com expresões chulas, pejorativas, amplamente conhecidas pela sociedade em geral, e muitas ofendem até mesmo à família ou remetem à ideia de sujo, impuro ou de uma pessoa sem importância social, um pária da sociedade.

Outro dado interessante, é quando julgam as ações dos colegas masculinos, normalmente alguns comportamentos podem ser considerados como ruins, pois são caracterizados com outros termos igualmente pejorativos. 
Outro meio que os alunos utilizam para ofender é com gestos obscenos geralmente para responder a uma brincadeira ofensiva ou chacota. Muitos destes são usados para zombar algum aluno que sofreu uma repreensão do professor, diretora ou coordenadora da escola, ou que tenha sido vítima de alguma chacota ou prejudicado em alguma coisa material/emocional.

Um caso observado durante uma aula foi quando uma menina estava usando touca, dentro da qual escondeu o próprio cabelo e dois alunos do gênero masculino a chamaram de "menininho", com tom jocoso. Outro caso observado foi o uso de uma caneta de cor rosa por aluno do gênero masculino. Um colega dele fez a seguinte observação em tom de ironia: "ele adora esta caneta", dando a ideia de que aquele menino gostava de utilizar um acessório de uma cor que representa o feminino.

Em das aulas, durante a uma apresentação de trabalho de alunos sobre a Rússia, foi citada a lei que criminaliza e proíbe a manifestação da homossexualidade, um dos alunos presentes fez o seguinte comentário na sala de aula: "está certo, gay tem que morrer".

Ainda sobre esse tipo de comentários, expressões homofóbicas de cunho preconceituoso foram encontradas nas portas dos banheiros masculinos, além de desenhos obscenos no lado interno das portas dos banheiros de uso individual.

Um dos pesquisadores, por usar esmalte nas unhas, e nessa ocasião estava usando esmalte vermelho, foi motivo de comentários entre os participantes da pesquisa, chegando mesmo a falarem que "da próxima vez ele vai aparecer de cílios postiços". Um dos alunos desenhou em um papel uma mão com unhas pintadas de vermelho e repassou aos demais. Na verdade, houve toda uma chacota em torno do fato. Posteriormente, o referido desenho foi entregue ao pesquisador. 
Observa-se que muitos desses meios de ofensa e chacota encontrados em brincadeiras, remetem ao ato sexual, ao gênero e à homossexualidade.

Importante se colocar que a reprodução desses preconceitos não é apenas entre alunos. As autoridades escolares como professores, coordenadores e diretora não veem isso como um problema que a escola tem que enfrentar. Na visão dos professores, coordenadores e da direção, a homofobia não faz parte da rotina escolar, e essas brincadeiras, embora aconteçam à vista de todos, nunca são problematizadas como conteúdo das disciplinas ou da transversalidade do currículo. Simplesmente não se toca no assunto, pois este parece bastante melindroso e produz certos conflitos indesejáveis a serem evitados e não estimulados.

Isso pode ser verificado em um caso que ocorreu o período da coleta de dados. Tratava-se de uma aluna ainda pré-adolescente, que se declarou apaixonada por uma professora da escola, sendo que algumas vezes ela expressava isso em sala de aula em meio à turma. Os demais alunos não se importaram muito com isso, pois é comum, entre eles, falar para os professores a expressão "eu te amo". Ao que tudo indica, isso apenas é uma demonstração de carinho que foi observado várias vezes durante a pesquisa. No entanto esse caso veio à tona como uma paixão da aluna pela professora. A solução encontrada por umas das coordenadoras da escola para resolver a questão, seria de sua exclusão, caso a situação persistisse.

O trabalho realizado nesse campo de pesquisa, a escola, suscitou a ideia de que desde a infância há a reprodução de uma educação que tende a seguir certos padrões impostos pela sociedade no que tange à sexualidade. Há uma divisão comportamental, da qual meninos devem agir de uma maneira e meninas de outra. Isso pode ser verificado nas aulas de Educação Física. 
As aulas são ministradas conjuntamente para os dois gêneros, no entanto as separações entre eles são bastante comuns, como exemplo, na organização das filas para entrar e sair da quadra, já que estas são dispostas em duas, classificadas por gênero. A quadra e as atividades de recreação e esportivas são divididas conforme o gênero. Raramente, se aplica uma atividade na qual todos podem participar.

Certos exercícios como a corrida, os meninos fazem separados das meninas. Nas brincadeiras com bola, os alunos são livres para brincar com o que quiser, mas os próprios alunos se dividem em brincadeiras para meninos (como jogar futebol) e para meninas (vôlei). Quando se aplica jogos em que meninos jogam contra meninas, e se eles perdem, via de regra todos os garotos reclamam do resultado, arranjando explicações para a derrota, a mais comum era de que haviam sido roubados e que as meninas não seguiam as regras ou não as entendiam. Salientase que a definição das atividades das aulas de Educação Física, embora fosse uma decisão coletiva entre professor e alunos, observou-se, que estas sempre eram uma discussão animada entre os garotos; as meninas, normalmente não se interessavam em participar desse debate, fazendo apenas comentários esporádicos, mas sem poder de decisão.

Esse modelo escolar acaba reforçando a aprendizagem de uma sociedade permeada pela dominação do masculino em detrimento do feminino. Desse modo, a escola pode ser vista como a reprodução do mundo social ao qual ela está intimamente vinculada numa perspectivada da elaboração e legitimação dos saberes produzidos pelo mundo social.

Em seus estudos, Pierre Bourdieu esforça-se em compor instrumentos que auxiliem na interpretação desse mundo social. No livro "A Dominação Masculina" (2002) o autor recorrerá à sua teoria sobre a violência simbólica, que agiria regulando os sistemas de pensamento e das percepções visíveis acerca dos corpos, procurando naturalizar o androcentrismo. Para tal empreendimento analisa como a desigual- 
Bullying escolar: a violência e preconceito nas formas do bullying entre estudantes do ensino fundamental em Campo Grande, MS

dade entre os sexos teria se constituído, se produzido, e os esquemas através dos quais é ela percebida.

Assim, inicia um estudo etnográfico da sociedade Kabília, na Argélia e pesquisa a conexão existente entre as estruturas de dominação objetivas e cognitivas, na qual se baseará a divisão entre os sexos e consequentemente se efetuará a organização do campo social. Essa divisão assimétrica entre masculino e feminino, dentro de um sistema simbólico, será aplicada a todas as coisas como princípio de visão e divisão sexualizantes. Nas palavras do autor:

Se a relação sexual se mostra, como uma relação social de dominação é porque ela está construída através do princípio de divisão sexual entre o masculino, ativo, e o feminino, passivo, e porque este princípio cria, organiza, expressa e dirige o desejo [...]. (BOURDIEU, 2002, p. 15).

No caso da homossexualidade, em que a reciprocidade dos papéis sexuais se torna possível, desvelando-se as condições sociais do uso dos corpos e a constituição da heterossexualidade como padrão universal de toda prática sexual, a transgressão sexual significa uma ameaça de extrema gravidade, visto que encerra uma agonística em torno da virilidade ${ }^{2}$ masculina.

A forma particular de dominação simbólica de que são vítimas os homossexuais, marcados por um estigma que, à diferença da cor da pele ou da feminilidade, pode ser ocultado (ou exibido), impõe-se através de atos coletivos de categorização que dão margem a diferenças significativas, negativamente marcadas, e com isso a grupos ou categorias sociais estigmatizados. Como em certos tipos de racismo, ele assume, no caso, a forma de uma negação de sua existência pública visível. (BOURDIEU, 2002, p. 70).

${ }^{2}$ A virilidade em Bourdieu pode ser entendida como capacidade reprodutiva, sexual
e social, mas também como aptidão ao combate e ao exercício da violência (sobre-
tudo em caso de vingança) é, acima de tudo, uma carga (BOURDIEU, 2002, p. 32). 
O privilégio masculino tem sua contrapartida na imposição de que todo homem tem o dever constante de afirmar sua virilidade, porque se temem os medos que a feminilidade suscita. Neste sentido:

Semelhante à nobreza, a honra- que se inscreveu no corpo sob forma de um conjunto de disposições aparentemente naturais, muitas vezes visíveis na maneira peculiar de se manter de pé, de aprumar o corpo, de erguer a cabeça, de uma atitude, uma postura, as quais corresponde uma maneira de pensar e de agir, um ethos, uma crença, etc. (BOURDIEU, 2002, p. 31).

Em outro momento Bourdieu reforça essa ideia dizendo:

Tudo concorre, assim para fazer do ideal impossível de virilidade o princípio de uma enorme vulnerabilidade. É esta que leva, paradoxalmente, ao investimento obrigatório por vezes, em todos os jogos de violência masculinos, tais como em nossas sociedades os esportes, e mais especialmente os que são mais adequados a produzir os signos visíveis da masculinidade para manifestar, bem como testar, as qualidade ditas viris, como os esportes de luta. (BOURDIEU, 2002, p. 32).

A investigação feita por Bourdieu permite uma análise crítica das questões de gênero, visto que concebe uma organização social simbólica do mundo a partir de uma estrutura binária de classificação do masculino e feminino. Contribuindo extraordinariamente para este processo estariam instâncias como a família, a igreja e a escola que, durante o procedimento de socialização e formação, atuariam sobre as estruturas inconscientes dos indivíduos. Para Bourdieu:

[...] os gêneros, longe de serem simples papéis sociais que se podem representar à vontade (tal como "drag queens"), são inscritos no corpo e no universo onde têm sua força. É a ordem dos gêneros que funda a eficácia performativa das palavrasespecialmente dos insultos-, e é esta ordem que resiste às definições falsamente revolucionárias do voluntarismo subversivo. (BOURDIEU, 2002, p. 51). 
Bullying escolar: a violência e preconceito nas formas do bullying entre estudantes do ensino fundamental em Campo Grande, MS

Além da reprodução de uma educação sexista no ambiente escolar, acaba-se por reforçar afirmação de um mundo social que tem a heteronormatividade como norma, o que pode ser visto nas piadas e nos insultos.

A junção da palavra, "hetero" que em Grego quer dizer "diferente" e "norma" que em Latim quer dizer "esquadro", constituem a formação da palavra heteronormatividade, ou seja, um conjunto de ações, relações e situações praticadas entre pessoas de sexos opostos. Assim, a sexualidade e identidade de gênero deveriam se esquadrar dentro dos moldes da heteronormatividade, sendo esta a única orientação sexual considerada "normal". A grande discussão em torno dessa palavra é a limitação que ela impõe, uma vez que implica em uma série de proibições que acabam dando origem a discriminações, preconceitos e, consequentemente, à homofobia.

As piadas, zoações e insultos que se remetem à sexualidade são uma forma de normatização, ou seja, uma forma de reprodução da heteronormatividade. Segundo Miskolci (2012, p. 44-45):

A heteronormatividade é um regime de visibilidade, ou seja, um modelo social regulador das formas como as pessoas se relacionam. Em nossos dias, a sociedade até permite, minimamente, por sinal, que as pessoas se relacionem com pessoas do mesmo sexo; portanto, ao menos para alguns estratos sociais privilegiados, já não vivemos mais em pleno domínio da heterossexualidade compulsória. Nas classes médias e altas urbanas, sobretudo metropolitanas, ganhou clara visibilidade a existência de pessoas que se interessam por outras do mesmo sexo. Nesse contexto, não é possível dizer que se nega a elas a homossexualidade, mas a sociedade ainda exige o cumprimento das expectativas com relação ao gênero e a um estilo de vida que mantem a heterossexualidade como um modelo inquestionável para todos/as.

Para Miskolci (2012), a escola possui um papel importante na reprodução da heteronormatividade. 
Em suma, é no ambiente escolar que os ideais coletivos sobre como deveríamos ser começam a aparecer como demandas e até mesmo como imposições, muitas vezes de forma muito violenta. (MISKOLCI, 2012, p. 40-41).

Essa forma violenta de normatização que ocorre no ambiente escolar é denominada atualmente de bullying.

O bullying não foi inventado nos últimos anos, o que mudou foi nossa sensibilidade com relação às formas de violência que ele expressa. A escola era partícipe do assédio moral de tal forma que, normalmente, a educação era bullying: você entrava e se enquadrava. Havia um currículo oculto, um processo não dito, não explicitado, não colocado nos textos, mas que estava na própria estrutura do aprendizado, nas relações interpessoais, até na própria estrutura arquitetônica, que continua a ser normalizadora. (MISKOLCl, 2012, p. 41).

O bullying é caracterizado também não só pela violência física, mas por expressões como riso, olhares, feições de desprezo e até a exclusão da pessoa que sofre esta violência:

Como se sabe, os indivíduos são resultado de suas relações estabelecidas em sociedade. Somos e nos construímos em contato com os outros. Nesse sentido, a discriminação homofóbica chega até a escola de várias formas, podendo ser simétrica - entre alunos, jovens da mesma idade ou do mesmo ano escolar - ou assimétrica, vinda de brincadeiras, risos, silêncios ou mesmo da indiferença dos professores ou funcionários da instituição que deveriam educá-los e protegê-los. (BORGES et al., 2011, p. 23).

Essas brincadeiras, mesmo que não possuam uma intenção consciente de agredir, reproduzem uma violência contra homossexuais. Dinis (2011) utiliza um conceito de Baptista (2009) para ilustrar essa violência, o conceito de "amolador de faca":

O fio da faca que esquarteja, ou o tiro certeiro nos olhos, possui aliados, agentes sem rostos que preparam o solo para esses 
sinistros atos. Sem cara ou personalidade, podem ser encontrados em discursos, textos, falas, modos de viver, modos de pensar que circulam entre famílias, jornalistas, prefeitos, artistas, padres, psicanalistas etc. Destituídos de aparente crueldade, tais aliados amolam a faca e enfraquecem a vítima, reduzindo-a a pobre coitado, cúmplice do ato, carente de cuidado, fraco e estranho a nós, estranho a uma condição humana plenamente viva. (BAPTISTA, 2009 apud DINIS, 2011, p. 44).

Assim, ao se fazer uma brincadeira que coloque a homossexualidade como um comportamento pejorativo, a pessoa que a fez está "amolando uma faca":

Embora não empunhem a arma, nem a faca que provoca diariamente o assassinato de pessoas que representam as minorias sexuais no Brasil, eles (as) são os (as) amoladores (as) de facas que colaboram indiretamente para tal genocídio, já que entender a homossexualidade como pecado, profanação do corpo e da sexualidade, como anormalidade e desvio de comportamento - discursos importados da religião, da mídia e das ciências psicológicas - são também as principais justificativas utilizadas por assassinos em série ou grupos de extermínio de travestis, transexuais, bissexuais, gays e lésbicas no Brasil. (DINIS, 2011, p. 46-47).

A piada se torna então uma forma de coerção direcionada a uma pessoa ou grupo que escapam à normatividade hegemônica, como demonstra Gomes e Lucca (2011, p. 99):

A "piadinha", a "chacota" ou a repreensão direta por parte da família e de outros grupos importantes para o indivíduo quanto a um comportamento indesejável (como o menino que brinca com meninas e com brincadeiras específicas de meninas, o jeito "efeminado" etc) funcionam como um importante mecanismo de coerção social que é parte do processo de elaboração/construção da identidade homoerótica, o que não equivale dizer, entretanto, que estes mesmos fatores coercitivos determinem a orientação sexual das pessoas. 
Essas questões já eram tratadas por Foucault (1987; 1989) na França, em suas obras "Vigiar e punir" e "A história da sexualidade I: a vontade de saber".

Em "Vigiar e punir", Foucault (1987) coloca o papel dos colégios, escolas e internatos para a construção da disciplina normalizadora sobre os corpos para que estes se tornem produtivos, sendo a implantação dessa economia da disciplina iniciada a partir do século XVIII:

O momento histórico das disciplinas é o momento que nasce uma arte do corpo humano, que visa não unicamente o aumento de suas habilidades, nem tampouco aprofundar sua sujeição, mas a formação de uma relação que no mesmo mecanismo o torna tanto mais obediente quanto é mais útil, e inversamente. Forma-se então uma política das coerções que são um trabalho sobre o corpo, uma manipulação calculada de seus elementos, de seus gestos, de seus comportamentos. [...] A "invenção" dessa nova anatomia política não deve ser entendida como uma descoberta súbita. Mas como uma multiplicidade de processos muitas vezes mínimos, de origens diferentes, de localizações esparsas, que se recordam, se repetem, ou se imitam, apoiam-se uns sobre os outros, distinguem-se segundo seu campo de aplicação, entram em convergência e esboçam aos poucos a fachada de um método geral. Encontramo-los em funcionamentos nos colégios, muito cedo; mais tarde nas escolas primárias. (FOUCAULT, 1987, p. 119).

A ciência possui papel fundamental na construção desses corpos, que classifica os corpos e comportamentos como corretos e errados, saudáveis ou doentes, normais ou anormais. Além da normatização dos corpos, esta ciência, denominada por Foucault (1989) de Scientia sexualis, classifica as sexualidades consideradas normais e anormais:

O crescimento das perversões não é um tema moralizador que acaso tenha obcecado os espíritos escrupulosos dos vitorianos. É o produto real da interferência de um tipo de poder sobre os 
corpos e seus prazeres. Talvez o Ocidente não tenha sido capaz de inventar novos prazeres e, sem dúvida, não descobriu vícios inéditos, mas definiu novas regras no jogo dos poderes e dos prazeres: nele se configurou a fisionomia rígida das perversões. (FOUCAULT, 1989, p. 55-56).

Segundo Foucault (1989), a Scientia sexualis formou um dispositivo da sexualidade, ou um discurso de saber-poder:

A sexualidade é o nome que se pode dar a um dispositivo histórico: não à realidade subterrânea que se apreende com dificuldade, mas à grande rede da superfície em que a estimulação dos corpos, a intensificação dos prazeres, a incitação ao discurso, a formação dos conhecimentos, o reforço dos controles e das resistências, encadeiam-se uns aos outros, segundo algumas grandes estratégias de saber e de poder. (FOUCAULT, 1989, p. 116-117).

Assim, as sexualidades consideradas dissidentes, como a homossexualidade, foram nomeadas, classificadas e colocadas no âmbito do desvio e da patologia. O livro "Medicina legal" de Genival Veloso de França (1985) evidencia como essa ideia de a homossexualidade ser uma patologia estava presente até pouco tempo.

Para nós, o homossexualismo, por si mesmo, é a prova indiscutível de uma personalidade anormal, pelas profundas modificações do caráter e da afetividade. [...] Seja qual for sua etiologia, o anormal necessita de tratamento e deve ser considerado como um caso estritamente médico. (FRANÇA, 1985, p. 167).

Além disso, a homossexualidade estava presente na Classificação Internacional das Doenças (CID) como código 302.0 até ser retirada em 1990.

Apesar de ter sido retirada, a ideia da homossexualidade como um comportamento anormal ainda é reproduzida devido ao sistema de visibilidade hegemônico, a heteronormatividade com ênfase no masculino, como citado anteriormente. 
A disciplina de Educação Física é um dos meios de a escola construir as relações de gênero. De acordo com as observações, a quadra, local onde ocorrem estsas aulas, se torna um ambiente masculino, pois os meninos a utilizarão para atividades físicas como corrida e futebol, enquanto as meninas ficam na periferia da quadra, sem interesse nas atividades. Mesmo que pudessem participar de atividades físicas, elas não demonstram interesse em fazê-lo, pois as atividades são sempre decididas e organizadas pelos meninos, que procuram rejeitar a presença feminina.

Através dos dados, observa-se como as atividades de educação física naturalizam o binarismo de gênero e enrijecem as identidades do "ser homem" e "ser mulher".

Uma forma de construção da masculinidade e sua reprodução pode ser observada em diversas brincadeiras entre os meninos, as quais consistem em ameaças de briga, socos e chutes. Esses casos demonstram a constituição da imagem masculina construída pelo discurso heterossexista, que enrijece e naturalizam a identidade "ser homem", como demonstra Bordieu (2002), qual seja, o homem verdadeiramente homem é aquele que se sente obrigado a estar à altura da possibilidade que lhe é oferecida de fazer crescer sua honra buscando a glória e a distinção na esfera pública. Assim, o homem deve sempre comprovar sua força e virilidade para ser reconhecido como o verdadeiro homem.

Essas diversas brincadeiras, palavrões a atividades que naturalizam a identidade binária homem/mulher e a heterossexualidade produzem uma violência silenciosa na escola.

A invisibilidade da homossexualidade no ambiente escolar, ou não reconhecimento dessa problemática mesmo quando envolve a relação professor/aluno, assim como a violência verbal e simbólica retratada nas brincadeiras, palavrões e insultos, criam um ambiente bastante hostil a crianças e adolescentes LGBTs, tanto dentro da escola, 
como no reflexo dessa situação de vulnerabilidade social imposta a esse grupo de pessoas, impedindo-as vivenciar plenamente o direito à afetividade e à sexualidade.

\section{CONSIDERAÇÕES FINAIS}

Neste artigo, foi possível discutir que a principal forma de reprodução da heteronormatividade no ambiente escolar em questão é através de brincadeiras, xingamentos e insultos. Assim, apesar de serem consideradas inofensivas por estarem em tom jocoso, as brincadeiras se mostram como uma forma de violência simbólica homofóbica, em que o preconceito se disfarça com risadas.

Importante ressaltar que essa violência não foca apenas a homossexuais, pois "essas violências se dirigem a todos e todas, apenas em graus diferentes" (MISKOLCl, 2012, p. 34), assim como é importante não criar vítimas e algozes na reflexão, pois todos os sujeitos estão submetidos às normas heterossexistas. Por todos estarem sob a imposição da heteronormatividade, tanto hetero quanto homossexuais reproduzem essa norma.

Apesar disso, durante o trabalho de campo, não se pôde verificar se havia ou não alunos ou professores com uma identidade assumidamente LGBT, podendo estar ainda no "armário", e talvez, não se sintam seguros diante de um quadro hostilidade representado pela violência verbal, simbólica e/ou física:

Assim, pode também haver alunos de sexualidades consideradas dissidentes que não aceitam sua própria orientação devido à reprodução de brincadeiras homofóbicas que, enquanto alguns consideram como uma simples brincadeira, outros podem se sentir ofendidos e não assumirem sua orientação sexual ("sair do armário") por receio da repressão que possam vir a sofrer, inclusive dentro do ambiente escolar, considerado por alguns alunos como "pacífico", afinal, o ato de "sair do 
armário" não se resume apenas a "se assumir" (ir de dentro para fora), mas é necessário sair de vários "armários", pois o aluno deverá se assumir para os pais, para os colegas, para os professores, entre outros, ou seja, não é apenas de um único "armário" que a pessoa homossexual deve sair. (ZAMIAN DE CARVALHO; REIS, 2014, p. 204).

Brincadeiras com objetivo de ofender acabam por gerar medo nos grupos atingidos e receio de expressarem sua sexualidade livremente.

Há de se considerar que os professores têm pouca ou nenhuma disposição em tratar de temas como a sexualidade e das relações entre os gênero. Acreditam que esse é um assunto polêmico demais para ser tratado com crianças e adolescentes.

Sendo assim, um dos desafios para escola é subverter a noção de heteronormatividade, não se tornando apenas um agente passivo da norma, se repensar e se transformar de modo que não exclua os diferentes grupos subalternizados para que evite esses contextos de violência verbal, física, psicológica, simbólica, entre outros.

É necessário também se rediscutir o palavrão, em que este não deve ser tratado apenas como uma "falta de educação" ou falta de capital cultural (BOURDIEU, 2007), mas estudar seu conteúdo e o que ele carrega.

\section{REFERÊNCIAS}

BORGES, Z. N; PASSAMANI, G; OGLWEILER, M. I.; BULSING, M. Percepção de professoras de ensino médio e fundamental sobre a homofobia na escola em Santa Maria (Rio Grande do Sul/Brasil). Educar em Revista, Curitiba, PR, n. 39, p. 21-38, jan./abr. 2011.

BOURDIEU, Pierre. A distinção: crítica social do julgamento. Tradução de Daniela Kern e Guilherme J. F. Teixeira. São Paulo: Edusp; Porto Alegre, RS: Zouk, 2007. 
Bullying escolar: a violência e preconceito nas formas do bullying entre estudantes do ensino fundamental em Campo Grande, MS

. A dominação masculina. Rio de Janeiro: Bertrand Brasil, 2002.

DINIS, Nilson Fernandes. Homofobia e educação quando a omissão também é signo de violência. Educar em Revista, Curitiba, PR, n. 39, p. 39-50, jan./ abr. 2011.

FOOTE-WHYTE, William. Treinando a observação participante. In: GUIMARÃES, A. Z. (Org.). Desvendando as máscaras sociais. 1. ed. Rio de Janeiro: Francisco Alves, 1975. p. 77-87.

FOUCAULT, Michel. História da sexualidade I: a vontade de saber. Rio de Janeiro: Graal, 1989.

. Vigiar e punir: nascimento da prisão. Petrópolis, RJ: Vozes, 1987.

FRANÇA, Genival Veloso de. Medicina legal. 2. ed. Rio de Janeiro: Guanabara Koogan, 1985.

GOMES, A. M.; LUCCA, Paulo R. Uma luz no fim do armário: aspectos sociais da construção do homoerotismo. In: PASSAMANI, Guilherme R. (Org.). (Contra) pontos: ensaios de gênero, sexualidade e diversidade sexual. Campo Grande, MS: Editora UFMS, 2011. p. 93-103.

MALINOWSKI, B. Os argonautas do Pacífico Ocidental. 3. ed. São Paulo: Abril Cultural, 1984.

MISKOLCI, Richard. Teoria Queer: um aprendizado pelas diferenças. 2. ed. Belo Horizonte: Autêntica, 2012. v. 1, 84p.

ZAMIAN DE CARVALHO, G.; REIS, A. F. Homofobia e sexualidade: a agressividade do 'palavrão' como forma de manifestação do bullying no ambiente escolar. Interfaces da Educação, Paranaíba, MS, v. 5, n. 13, p. 194-207, 2014. 
